\title{
LA COAUTORÍA EN EL CÓDIGO PENAL A TRAVÉS DE UN SUPUESTO DE TENTATIVA DE HOMICIDIO
}

\author{
Alfonso Serrano Gómez \\ Profesor Emérito UNED
}

Sumario: I. Introducción.- II. Hechos en los que la sentencia que se comenta basa la coautoría.- III. Coautoría. Estudio doctrinal y jurisprudencial.- IV. Consideración final.-

\section{INTRODUCCIÓN}

Se hace un estudio de la coautoría comentando la sentencia de la Sección 23 de la Audiencia Provincial de Madrid de 1 de septiembre de 2010, que condenó por un delito de tentativa de homicidio y lesiones.

Dispone el párrafo primero del art. 28 del Código penal que «son autores quienes realizan el hecho por sí solos»(autor individual), «conjuntamente» (coautoría), "o por medio de otro del que se sirven como instrumento» (autor mediato).

Establece el párrafo segundo de este artículo: «También serán considerados autores: a) los que inducen directamente a otro u otros a ejecutarlo. b) los que cooperan a su ejecución con un acto sin el cual no se habría efectuado».

Los penalistas valoran e interpretan el Derecho sin entrar en el procedimiento que lleva a probar la comisión del delito e imposición de la pena. Esta parte es compleja, de la que se ocupa especialmente el Derecho procesal, materia que deben conocer los penalistas, pues ello les permitiría una mejor valoración de muchos principios y conceptos de la ciencia penal. Llegar a una sentencia correcta no es fácil por las dificultades que lleva consigo especialmente todo lo relacionado con la prueba; es frecuente que todas o algunas de las partes 
mientan o intenten alterar la realidad a lo largo de la instrucción y durante la celebración de la vista oral del juicio. A veces las sentencias condenatorias carecen de pruebas suficientes, lo que permite presentar recursos, alegando presunción de inocencia, en base a lo dispuesto en el art. 852 de la LECrim., 5.4 de la Ley Orgánica del Poder Judicial y 24.2 de la Constitución. La referencia que se hace en el artículo 741 de la LECrim., de la valoración de la prueba «según su conciencia» por el juzgador tiene muchos riesgos, ya que los criterios sobre los mismos hechos pueden ser dispares ${ }^{1}$. En el proceso penal tienen que observarse todas las garantías, pues en otro caso se puede condenar a un inocente, lo que es muy grave, o absolver a culpables en general por falta de pruebas, que aun siendo frecuente tiene menos importancia. A veces el juzgador dicta sentencias condenatorias que no se ajustan a Derecho, lo que puede llevar a un delito de prevaricación que normalmente será por imprudencia o ignorancia inexcusable ${ }^{2}$. Un eminente magistrado que pasó por todos los puestos de la Administración de Justicia, incluida la Sala de lo Penal del Tribunal Supremo, se ocupó de poner de relieve la variedad de sentencias, en un trabajo titulado: "De la clasificación de las sentencias, y en particular de las muy minoritarias que dictan algunos jueces para aligerar su esfuerzo y gozar de buena fama entre ignorantes y otras gentes de fácil contentar (A modo de despedida)»3. Hace una clasificación de 28 tipos de sentencias ${ }^{4}$, de las que destacamos la que califica como "polivalente», "prefabricada», "precocinada» o "de refrito» en las que una vez redactadas el Juez puede dictar el fallo que más le

${ }^{1}$ Dispone el párrafo primero del art. 741 de la LECrim.: «El Tribunal, apreciando, según su conciencia las pruebas practicadas en el juicio, las razones expuestas por la acusación y la defensa y lo manifestado por los mismos procesados, dictará sentencia dentro del término fijado en esta Ley».

${ }^{2}$ Se castiga en el art. 446 del CP al «Juez o Magistrado que, a sabiendas dictare sentencia o resolución injusta ...». La pena varía "si se trata de sentencia injusta contra el reo en causa criminal por delito ... o en proceso por falta ... o cuando dictara cualquier otra sentencia o resolución injustas». El art. 447 recoge: «El Juez o Magistrado que por imprudencia grave o ignorancia inexcusable dictara sentencia o resolución manifiestamente injusta incurrirá en la pena de inhabilitación especial para empleo o cargo público por tiempo de dos a seis años».

${ }^{3}$ Manzanares Samaniego, J.L., en Actualidad penal, 2003-3, págs. 1167 y ss.

${ }^{4}$ Clasifica las sentencias en los siguientes modelos: 1. circular; 2 . policiaca o a lo Agatha Christie; 3. empanada; 4. al descabello; 5 . polivalente, prefabricada, precocinada o de refrito; 6. al gusto del chef; 7 a la violeta; 8 . a lo moralina; 9 . gratuita; 10 . al alicón; 11. escolástica; 12. lecho de Procusto; 13. flamencas o colombinas; 14. ladrillo; 15. al nombre propio; 16 . Frankenstein; 17 . sentencia legislativa; 18 . al gerundio; 19. al jurado español; 20. sentencias cortas y sentencias largas; 21 . sonda; 22 . resurrection pie; 23 . porosa o de los vasos comunicantes; 24 . de olla podrida; 25 . truncada, coja, mutilada o incompleta; 26 . putativa; 27 . formulario; 28 . a la buena de Dios. 
guste $^{5}$ : condenar o absolver. A este catálogo podrían añadirse otro tipo de sentencias dictadas por presiones o intereses políticos, así como algunas absolutorias por no acusar el Ministerio Fiscal, las que un Magistrado del Tribunal Supremo denomina «jurisprudencia de oportunidad ${ }^{6}$.

Los Jueces y Fiscales pueden jugar de forma parcial durante la instrucción de un procedimiento, incluso en el acto de la vista oral. Los Jueces pueden rechazar o denegar la práctica de diligencias de prueba presentadas por las partes -aunque ello es recurrible-, así como dirigir el procedimiento en una u otra dirección buscando ventaja para alguna de las partes, generalmente los presuntos culpables. En el interrogatorio de los testigos, a los que no se les permite que les acompañe un letrado, puede llegarse a conseguir declaraciones falsas,

\footnotetext{
${ }^{5}$ ManZanares Samaniego, , ob. cit., pág. 1169 escribe: «5. La sentencia 'polivalente', 'prefabricada', 'precocinada' o 'de refrito' ofrece, como sus nombres indican, grandes ventajas. Una vez redactadas las enojosas consideraciones o fundamentos de derecho, se puede elegir, ya con calma, el fallo que más guste. Así, por ejemplo, se vierten profundas observaciones sobre la imprudencia, sus clases y sus diferencias con el dolo eventual. Luego, como bálsamo de Fierabrás, se recurre a la fórmula mágica de 'aplicando la anterior doctrina al caso de autos'. Y finalmente se saca de la chistera un conejo blanco o negro, según demande la justicia material, recta e informalmente entendida. La sentencia 'polivalente' ahorra esfuerzos innecesarios y facilita por igual el acierto o el error de última hora, a la vez que previene lamentables retrasos. Es técnica muy recomendable para jueces pragmáticos, gandules y dubitativos. Se presta al estudio del Derecho penal conforme al sistema de casos similares y, por lo que tiene de 'suspense' hasta el último momento, puede solaparse con la sentencia policíaca».

${ }^{6}$ Jorge BARREIRO, A., «Jurisprudencia de oportunidad: el ocaso de la acción popular», en $J p D$, núm. 61/2008, págs. 9 y ss., escribe en pág. 15: «Lo más curioso de todo es que los mismos políticos que en no pocos casos jalean, apoyados por supuesto por alguno de los grupos mediáticos, la actuación de algunos jueces, después acaban afirmando que los jueces carecen de imparcialidad y de independencia de criterio para controlar las instrumentalizaciones del proceso por las acusaciones populares (...) El caso que ahora nos ocupa constituye un ejemplo de una asombrosa plasticidad descriptiva sobre lo que se acaba de exponer. Se trata de un supuesto en que los altos dirigentes de la entidad bancaria más importante del país y otros 28 ciudadanos han sido imputados por una serie de delitos en cadena que afectan fundamentalmente a la Hacienda Pública, es decir, al patrimonio común de los ciudadanos. Se transforma el procedimiento contra ellos. El Ministerio Fiscal y la Abogacía del Estado no acusan, y dos acusaciones populares sí lo hacen. La Juez de Instrucción y la Sala competente de la Audiencia Nacional -cuatro jueces en instancias distintas- sí encuentran indicios criminales contra los imputados. Y cuando, después de quince años, se está iniciando la vista oral del juicio, otra Sala distinta de la Audiencia Nacional implanta una nueva doctrina procesal que cercena a partir de ahora de forma capital la intervención autónoma de las acusaciones populares en más del noventa por ciento de los procesos penales. Por último, el Tribunal Supremo avala su decisión, muy preocupado, eso sí, por la desconfianza que muestran unos atrevidos y suspicaces ciudadanos hacia la intervención del Ministerio Fiscal como monopolizador de la acción penal».
} 
o al menos dudosas ${ }^{7}$; incluso cabe decretar la imputación de alguna persona sin pruebas suficientes, con lo que el instructor puede cometer un delito de prevaricación ${ }^{8}$. Los Fiscales, debido a su organización jerárquica ${ }^{9}$, que debió de desaparecer hace muchos años, en alguna ocasión por orden de sus superiores podrían ejercer acciones penales sin base indiciaria suficiente, abstenerse de hacerlo pese a existir razones para ello, modificar o retirar acusaciones; no obstante pueden y deben negarse ${ }^{10}$. Estos comportamientos podrían ser constitutivos de delito ${ }^{11}$. En algún caso, da la impresión de que la acu-

${ }^{7}$ En las diligencias previas 678/2006, instruidas en un Juzgado de Madrid, la permisibilidad de excesos del instructor con respecto de las acusaciones llevó a que uno de los letrados de la defensa incorporado meses más tarde de esos acontecimientos (2009) dirigiera un escrito al Juez instructor en el que decía: «De acuerdo con el artículo 439 de la Ley de Enjuiciamiento Criminal, 'no se harán al testigo preguntas capciosas ni sugestivas, ni se empleará coacción, engaño, promesa ni artificio alguno para obligarle o inducirle a declarar en determinado sentido. Con los debidos respetos y con ánimo de estricta defensa, pero con toda firmeza, debemos decir que a juicio de esta representación, una vez visualizadas algunas de las declaraciones de testigos que se han realizado con anterioridad a nuestra personación -llevada a cabo tras conocer en Internet el Auto de 6 de Mayo-, que el precepto anterior ha sido vulnerado de modo reiterado en los interrogatorios por una acusación 'popular' y una acusación 'particular', con la finalidad de que los testigos, sintiéndose clara e incomprensiblemente atacados, y totalmente confundidos pongan en su boca palabras que no son suyas. Baste a título de ejemplo citar la declaración de Luis, quien tras haber sido llamado a las dependencias policiales, al Juzgado para ratificar la denuncia y, posteriormente, con largas esperas, nuevamente al Juzgado para declarar, cansado ante tanta molestia y agresividad en el interrogatorio, con múltiples reiteraciones de preguntas, llega a decir 'lo que deseo es que esto acabe' 'ahora ya desconfío'. Terminando la manipulación del asustando testigo, con la pregunta de si ¿considera que le engañaron?, al que responde con un asustando 'creo que si'. Nuevamente debemos afirmar que con tales mimbres no se puede afirmar que existan indicios de engaño ni delito alguno. Lo que sí consideramos es que la grabación de la declaración de Luis podrá servir para que en la Facultad de Derecho puedan estudiar de forma práctica el art. 439 de la Ley de Enjuiciamiento Criminal, pero no para fundamentar la pretendida imputación».

${ }^{8}$ Vid Serrano Gómez A., «La condición de imputado en el proceso penal», en $\mathrm{La}$ Ley, número 4843, julio 1999. Vid. supra nota 2.

${ }^{9}$ La dependencia jerárquica se recoge en el art. 2.1 del Estatuto Orgánico del Ministerio Fiscal, que dedica el cap. II de su Tít. II a la «Unidad y dependencia del Ministerio Fiscal».

${ }^{10}$ Dispone el art. 27.1 del Estatuto Orgánico: «El Fiscal que recibiere una orden o instrucción que considere contraria a las leyes o que, por cualquier otro motivo estime improcedente, se lo hará saber así, mediante informe razonado, a su Fiscal Jefe...». En el apartado 2 se recoge: «Si el superior se ratificase en sus instrucciones lo hará por escrito razonado con la expresa relevación de las responsabilidades que pudieran derivarse de su cumplimiento o bien encomendará a otro fiscal el despacho del asunto a que se refiera». El contenido de este apartado no afectará a la responsabilidad penal, de la que responderá igualmente quien dio la orden.

${ }^{11}$ Pueden cometer delitos de acusación y denuncia falsas (art. 456 Código penal) o la omisión del deber de perseguir delitos del art. 408. Ello afectaría también al superior que da la orden. 
sación fiscal no se sustenta en bases sólidas, pues ante la petición de penas privativas de libertad, que a veces son milenarias, los tribunales absuelven o ponen penas muy bajas ${ }^{12}$.

\section{HECHOS EN LOS QUE LA SENTENCIA QUE SE COMENTA BASA LA COAUTORÍA}

La sentencia de la Sección 23 de la Audiencia Provincial de Madrid de 1-09-2010 recoge en el único de los hechos probados:

1.- «En la madrugada del día 2 de noviembre de 2003 sobre las 2.00 horas los acusados Alejandro y Antonio se dirigieron en unión de otras personas, cuya identidad se desconoce, que portaban cadenas y palos se dirigieron al Parque Azorín donde por motivos que se desconocen, iniciaron una discusión con otro grupo de jóvenes integrado por Víctor, Pedro, David y Saúl. En el transcurso de la misma, resultó agredido Víctor, motivo por el que se acercó Miguel con intención de separar a Víctor de su agresor, en ese momento el acusado Alejandro pinchó con una navaja en la espalda a Miguel Ángel, enzarzándose en una pelea en la que ambos rodaron por el suelo y Alejandro siguió propinando a Miguel varios navajazos en la espalda, nuca y abdomen, con intención de causarle la muerte, al tiempo que el otro acusado Antonio participa con Alejandro en esta agresión, golpeando a Miguel con una cadena que impactó de refilón en su cabeza. A continuación se acercó Saúl para tratar de separar a los anteriores y en ese momento Alejandro le dio un navajazo en la espalda*.

Como consecuencia de lo anterior: Miguel resultó con múltiples heridas por arma blanca en tórax, abdomen, cuero cabelludo, que le afectaron a la cara posterior del hemotórax derecho y cara lateral y posterior del hemotórax izquierdo, herido profunda en región occisisto-vertical y heridas en ab-

${ }^{12}$ En el procedimiento seguido en la Audiencia Nacional por los actos terroristas del $11 \mathrm{M}$ en el que hubo 192 muertos, la petición del Fiscal para R.O. era prisión de 38.962 años, y fue absuelto. La petición para A.B. era de 38.960 años, siendo condenado a 18; para H.H. de 38.962 años, siendo condenado a 15 . La petición fiscal para I.B. era de 38.962 años de prisión, fue condenado a 12. Por el contrario en el caso de J.Z. la condena fue de 42.917 años, y la petición fiscal de 38.960 años (hay que tener en cuenta que hubo acusaciones particulares). Vid. diario El Mundo de 18-07-2008, págs. $10 \mathrm{y} \mathrm{s}$.

"El subrayado es nuestro. 
domen izquierdo, de las que tardó en curar 26 días durante los que estuvo incapacitado para sus ocupaciones y 10 de ellos fueron de ingreso hospitalario y dos días en UCI pues precisó tratamiento médico, quirúrgico, hospitalario y psicoterapéutico. Le quedan como secuelas una gran cicatriz que recorre toda la región occipital y 10 cicatrices de 2 a $3 \mathrm{cms}$ en espalda y regiones axilares. El hemotórax lateral le hubiera ocasionado la muerte de no haber recibido atención hospitalaria urgente».

2.- La sentencia recoge en el fallo:

" $1^{\circ}$.-Debemos condenar y condenamos a Alejandro como autor responsable de un delito de homicidio en grado de tentativa con la atenuante de dilaciones indebidas a la pena de cinco años de prisión con la accesoria de inhabilitación especial para el derecho de sufragio pasivo durante el tiempo de la condena. Indemnizará a Saúl en 600 euros y a Miguel le indemnizará en 11.560 euros. Y al pago de una sexta parte de las costas procesales incluidas las de la acusación particular.

- Como autor responsable de un delito de lesiones con la atenuante de dilaciones indebidas, a la pena de dos años de prisión con la accesoria de inhabilitación especial para el derecho de sufragio pasivo durante el tiempo de la condena. Y al pago de una tercera parte de las costas procesales.

$2^{\circ}$.- Debemos condenar y condenamos a Antonio como autor responsable de un delito de homicidio en grado de tentativa con la atenuante de dilaciones indebidas a la pena de cinco años de prisión con la accesoria de inhabilitación especial para el derecho de sufragio pasivo durante el tiempo de la condena. Y al pago de una tercera parte de las costas procesales».

Dentro de la teoría jurídica del delito no hay posibilidad de argumentar que Antonio cometiera un delito de homicidio en grado de tentativa, ya que se limitó a realizar un solo acto, según se recoge en el párrafo anterior; impactar de refilón con una cadena en la cabeza de la víctima. No concurre ninguno de los elementos del delito, como se expondrá más adelante. No se prueba, ni hay ningún tipo de indicios, que justifiquen que hubo un pacto con el otro condenado para cometer el delito por el que se le condenó; ni que tuviera el dominio o condominio del hecho, ni en suma, que tuviera una participación causal y eficaz para la comisión del delito. 


\section{COAUTORÍA. ESTUDIO DOCTRINAL Y JURISPRUDENCIAL}

La referencia que se hace en los hechos probados de la sentencia con respecto de Antonio no pueden calificarse como tentativa de homicidio, pues se limitó a dar un golpe con una cadena a la víctima de "refilón»; esa fue su única intervención. No se recoge en los hechos: a) que hubiera acuerdo previo entre los dos condenados, b) que tuviera el dominio o condominio del hecho, c) que tuviera intención de causar la muerte del lesionado y d) ni su intervención tuvo ningún aporte causal, esencial o eficaz respecto del delito por el que se le condena.

Se limitó a impactar de refilón en la cabeza de la víctima con una cadena. Si hubiera tenido intención de colaborar eficazmente, como se exige en la coautoría, hubiera seguido golpeando a la víctima; en los hechos probados consta que llevó a cabo un solo acto, el de refilón con la cadena. A partir de ahí se desentiende de la pelea.

1. En la coautoría ha de concurrir una aportación causal, esencial, eficaz, en la ejecución de los hechos. Esto no se da en la intervención de Antonio que se limitó únicamente a dar un golpe de refilón con una cadena. En este sentido se pronuncia tanto la doctrina como la jurisprudencia.

a) Postura de la doctrina.

Se pronuncia de forma unánime respecto a que en la coautoría tiene que concurrir una aportación causal, esencial, eficaz, en la ejecución de los hechos. Se cita a continuación, la postura de algunos autores.

- Bacigalupo Zapater escribe:

«Para la coautoría es decisivo una aportación objetiva al hecho por parte del coautor. Sólo mediante esta aportación se puede determinar si el partícipe tuvo o no el dominio del hecho y, en consecuencia, si es o no coautor. La aportación objetiva que determina la existencia de un co-dominio del hecho puede resumirse en una fórmula de utilización práctica: habrá co-dominio del hecho cada vez que el partícipe haya aportado una contribución al hecho total, en el estadio de la ejecución, de tal naturaleza que sin ella aquél no hubiera podido cometerse. Para el juicio sobre la dependencia de la consumación del hecho de la aportación del partícipe es decisivo el plan de realización tenido en cuenta por los autores» ${ }^{13}$.

13 Bacigalupo Zapater, E., Principios de Derecho penal. Parte General. Madrid: Akal, 1997, pág. 366. 
— Barja López de Quiroga, escribe:

«Un aporte esencial durante la ejecución dará lugar a la coautoría» ${ }^{14}$.

- Berdugo Gómez de la Torre y otros, escriben:

«El coautor debe realizar una aportación esencial para la consecución del resultado... será coautor aquel que posea el dominio funcional del hecho, aquel que intervenga condominando el hecho» ${ }^{15}$.

- Mir Puig escribe:

«Lo acertado es, pues, considerar coautores no sólo a los que ejecuten en sentido formal los elementos del tipo, sino a todos quienes aporten una parte esencial de la realización del plan durante la fase ejecutiva ${ }^{16}$.

- Muñoz Conde y García Arán dicen:

«El simple acuerdo de voluntades no basta. Es necesario que se contribuya de algún modo a la realización del tipo» ${ }^{17}$.

Se insiste una vez más que del contenido de los hechos probados no puede deducirse que hubo un aporte causal, esencial o eficaz de Antonio. Se recuerda que los hechos probados con respecto de él solamente recogen:

«Al tiempo que el otro acusado participa con Alejandro en esta agresión, golpeando a Miguel con una cadena que impactó de refilón en su cabeza».

Las sentencias en los hechos probados deben dejar claro la participación a efectos de la tipificación del delito por el que se condena, lo que no sucede en la que aquí se comenta. Por poner un ejemplo, citamos lo que recoge la sent. de 20-09-2005 ${ }^{18}$. Vid. también la de 19-02-2008 cita-

${ }^{14}$ Barja López de Quiroga, J., Comentarios al Código penal, (dir. Cobo del Rosal). Madrid: Edersa, 2000, tomo II, pág. 141.

${ }^{15}$ Berdugo Gómez de la Torre, I., y otros, Curso de Derecho penal. Parte general. Barcelona: Rubi, 2010, págs. 387. 397.

${ }^{16}$ Mir PuIG, S., Derecho penal. Parte general. Barcelona: Reppertor, 2010, pág.

${ }_{17}$ Muñoz Conde, F., y García Arán, C., Derecho penal. Parte general. Valencia: Tirant lo blanch, 2010, págs. 435.

${ }^{18}$ La Sección primera de la Audiencia Provincial de Madrid en sentencia de 30 de septiembre de 2004 condenó por homicidio a dos personas que actuaron como coautores. Recurrida la sentencia al TS fue confirmada en la ya indicada de 20 de septiembre de 2005. En el único hecho probado de la sentencia condenatoria se recoge: «Sobre las 20,10 horas del día 8 de junio de 2003 el acusado Millán en compañía de un menor de edad (juzgado por estos hechos en la jurisdicción de menores) y puestos de común acuerdo, portando al menos uno de ellos una navaja con pleno conocimiento del otro, para el caso de que fuese necesario utilizarla en el curso del apode- 
da por la que aquí comenta (el TS resuelve respecto de un recurso interpuesto contra una sentencia de la Audiencia Provincial de Barcelona). (Se recoge más adelante).

\section{b) Postura de la jurisprudencia}

La jurisprudencia se pronuncia en la misma línea de que los coautores han de colaborar con una aportación esencial, causal o eficaz, para la ejecución del delito. A este respecto se citan algunas sentencias.

- La sentencia del TS núm. 95/2008, de 14 de febrero (la cita la sentencia recurrida en el párrafo cuarto del tercero de los fundamentos jurídicos), en el penúltimo párrafo del quinto de sus fundamentos de derecho recoge:

«En el art. 28 C.P. como 'realización conjunta del hecho', que requiere, de una parte, la existencia de una decisión conjunta de ejecutar la acción delictiva como elemento subjetivo de la coautoría. $\underline{Y}$, por otra, el elemento objetivo constituido por una aportación material al hecho que pueda valorarse como una acción esencial y con relevancia causal del resultado producido»*.

Esta sentencia de 14-02-2008, como se indica en el párrafo anterior, se cita en el párrafo cuarto del fundamento jurídico tercero de la sentencia que se comenta, al ocuparse de la "participación adhesiva», que concurre "cuando el tercero se suma activa y eficazmente a la realización del delito ya iniciado por otros». Hace referencia a la «suma activa y eficazmente»".

— La sent. del TS núm. 468/2007, de 18 de mayo, en el penúltimo párrafo del quinto de sus fundamentos dice:

«Lo importante, en definitiva, es que cada individuo aporte una contribución objetiva y causal para la producción del hecho típico querido por todos. Lo único verdaderamente decisivo, en suma, es

ramiento que pretendían llevar a cabo, abordaron por la espalda y con la finalidad de despojar de sus pertenencias a la pareja de turistas formada por Fermín de 40 años y Alicia de 32 años madre de cuatro hijos, cuando caminaban por la calle Fernanflor de Madrid; mientras uno de ellos rodeó por el cuello al hombre y forcejeó con él, arrebatándole la cámara de vídeo que llevaba colgada al cuello, el otro se dirigió a la mujer y tras forcejear brevemente con ella, le asestó un navajazo, con ánimo de quitarle la vida, que entró por debajo de la parrilla costal y le atravesó el corazón, ocasionándole de modo inmediato e irreversible la muerte; tras el navajazo, le quitó el bolso que ella portaba y ambos salieron huyendo hacia el Paseo de las Cortes». En este caso, en los hechos probados, se hace constar que los dos sujetos que intervienen se habian puesto de acuerdo para cometer el delito, que al menos uno de ellos portaba una navaja, con conocimiento del otro, y que estaban de acuerdo en usarla si era necesario.

"El subrayado es nuestro. 
que la acción del coautor signifique un aporte causal a la realización del hecho propuesto»*.

— La sent. del TS 452/2008, de 10 de julio, cita en la línea que se viene manteniendo diversas sentencias desde 2003. Recoge en el párrafo sexto del sexto de sus fundamentos de derecho:

«Citemos, por último, la STS de 11 de marzo de 2003 en la que se establece que, la doctrina de esta Sala en materia de autoría conjunta (Sentencias de 9 de octubre 1998, núm. 1177/98, 14 de abril de 1999, núm. 573/1999, 10 de julio de 2000, núm. 1263/2000, 11 de septiembre de 2000, núm. 1240/2000, y 27 de septiembre de 2000, núm. 1486/2000, entre otras), señala que la nueva definición de la coautoría acogida en el art. 28 del Código penal 1995 como 'realización conjunta del hecho' implica que cada uno de los concertados para ejecutar el delito colabora con alguna aportación objetiva y causal, eficazmente dirigida a la consecución del fin conjunto». (En el mismo sentido la sent. del TS núm. 393/2008, de 26 de junio, párrafo penúltimo de su fundamento jurídico tercero)*.

- La sent. del TS núm. 563/2008, de 24 de septiembre recoge en el decimoséptimo de sus fundamentos de derecho:

«La realización conjunta del hecho implica que cada uno de los concertados para ejecutar el delito colaborar con alguna aportación objetiva y causal, eficazmente dirigida a la consecución del fin conjunto»*.

La sent. del TS núm. 915/2009, de 19 de octubre recoge en el segundo de sus fundamentos de derecho parte del contenido de otras sentencias referentes a la coautoría del art. 28 del Código penal haciendo referencia a la necesidad de una aportación eficaz al mismo en la fase ejecutiva, aportación objetiva y causal, aportaciones causales decisivas en el sentido que sigue:

"Apareciendo la autoría como un supuesto de 'división de trabajo', requiriendo, una decisión conjunta, un codominio del hecho, y una aportación eficaz al mismo en fase ejecutiva...

... nueva definición de la coautoría acogida en el art. 28 del Código Penal 1995 como 'realización conjunta del hecho' implica que cada uno de los concertados para ejecutar el delito colabora con alguna aportación objetiva y causal, eficazmente dirigida a la consecución del fin conjunto, es decir, al hecho delictivo...

... a la realización del delito se llega conjuntamente, por la agregación de las diversas aportaciones de los coautores, integradas en el plan común, siempre que se trate de aportaciones causales decisivas...»

"El subrayado es nuestro. 
Conclusión.- Según se desprende de los hechos probados y de la postura de la doctrina y de la jurisprudencia al respecto, la participación de Antonio no tuvo ninguna aportación esencial, causal o eficaz en el delito por el que se le condena. Hay que recordar una vez más que en los hechos probados solamente consta: "al tiempo que el otro acusado Antonio participa con Alejandro en esta agresión, golpeando a Miguel con una cadena que impactó de refilón en su cabeza».

\section{2.- Fundamentos jurídicos de la sentencia comentada.}

Se pasa a continuación a tratar de los fundamentos jurídicos de la sentencia que se comenta, para poner de manifiesto que el contenido de los mismos no justifican la condena de Antonio. En todo caso hay que tener en cuenta que la pieza clave en la sentencia son los hechos probados; los elementos del tipo objetivo del delito no pueden ser complementados en los fundamentos jurídicos.La sent. del TS 397/2008, de 1 de julio, recoge en el párrafo último del segundo de sus fundamentos de derecho:

«En el Pleno no jurisdiccional de la Sala Segunda que el 28.3.2006 adoptó el siguiente acuerdo»:

«Los elementos del tipo objetivo del delito incluidos los relativos a las circunstancias modificativas deben constar en todo caso en el apartado de hechos probados de la sentencia, sin que sea posible complementarlos con el contenido de la fundamentación jurídica»**.

La sent. del TS núm. 309/2008, de 30 de mayo, recoge en el párrafo tercero de su fundamento de derecho $7^{\circ} .5$ :

«Recordamos aquí algo que en los últimos veinte años esta sala ha dicho y repetido hasta la saciedad. En el contenido de las sentencias condenatorias penales la pieza clave es el relato de hechos proba$\underline{\operatorname{dos}^{19}}{ }^{19}$

a) El primero de los fundamentos jurídicos de la sentencia que se comenta se ocupa de la motivación fáctica.

${ }^{*}$ El subrayado es nuestro.

${ }^{19}$ Continúa diciendo la sentencia: «Si hay que motivar todas las sentencias (y los autos), es decir, si hay que expresar en el texto de la propia resolución las razones que justifiquen lo decidido en cada caso, cuando se trata de tales sentencias condenatorias es necesario decir el porqué de esos hechos probados y ello solo es posible haciendo un análisis de la actividad probatoria realizada en el proceso, de modo que quede de manifiesto la concreta prueba de cargo utilizada en cada caso». 
«MOTIVACIÓN FÁCTICA. Los hechos descritos en el apartado anterior vienen acreditados por las siguientes pruebas: las declaraciones de la víctima Miguel, en las que relata la agresión que sufrió y ha identificado a los dos acusados como las personas que le agredieron, Alejandro el que le dio los navajazos y Antonio el que le golpeó con una cadena; se practicaron las correspondientes ruedas de reconocimiento, en las que reconoció a cada uno de ellos como los autores de la agresión. Por su parte Saúl ha relatado que vio cómo una persona se echaba sobre Miguel, rodaron por el suelo, fue a separarles, había más de dos personas agrediendo a Miguel y el que estaba rodando con él se levantó con una navaja en la mano y se la clavo a él (a Saúl). Vio las caras de los agresores, Alejandro era el que llevaba la navaja y Antonio la cadena" ".

Comienza este fundamento jurídico diciendo: «los hechos descritos en el apartado anterior vienen acreditados por las siguientes pruebas...». Lo único que se dice con respecto a Antonio es:

La víctima Miguel relata la agresión que sufrió «las declaraciones de la víctima Miguel, en las que relata la agresión que sufrió y ha identificado a los dos acusados como las personas que le agredieron».

«Antonio el que le golpeó con una cadena»

«se practicaron las correspondientes ruedas de reconocimiento, en las que reconoció a cada uno de ellos como los autores de la agresión».

De lo anterior se desprende que la víctima se limitó a relatar la agresión sufrida y a reconocer a los dos que le agredieron, uno de ellos fue Antonio. Se recuerda que éste no hizo más que darle a la víctima de refilón con una cadena.

- Testigo Saúl:

«Vio las caras de los agresores, Alejandro era el que llevaba la navaja y Antonio la cadena».

Lo recogido en este primer motivo no representa el menor indicio para justificar la concurrencia de ninguno de los elementos del delito de homicidio en grado de tentativa por el que se condenó a Antonio. Como ya se apuntó, ni de los hechos probados, ni de este primer fundamento jurídico, ni del resto, puede deducirse: a) que hubiera acuerdo previo entre los dos condenados, b) que Antonio tuviera el dominio o condominio del hecho, c) que tuviera la más mínima intención de causar la muerte del lesionado y d) que su intervención conllevara algún aporte causal, eficaz o esencial respecto del delito por el que se le condena. Nada de ello concurre.

\footnotetext{
* El subrayado es nuestro.
} 
b) Ánimo de matar. La sentencia que aquí se comenta dedica su fundamento jurídico segundo a justificar que hubo intención de matar (animus necandi) para lo que en el párrafo primero tiene en cuenta la jurisprudencia del Tribunal Supremo -citando varias sentencias-, que a efectos de determinar la intención se tiene en cuenta el arma o instrumentos empleados, zona del cuerpo a la que se dirige el ataque, intensidad del golpe o golpes en que consiste la agresión, repetición de golpes, «y aunque todos los datos deben ser considerados, tienen especial interés, por su importante significado, el arma empleada, la forma de agresión y el lugar del cuerpo al que ha sido dirigida» ${ }^{20}$.

En este fundamento jurídico segundo la sentencia no menciona para nada el nombre de Antonio. Tampoco se hace ninguna referencia a la cadena, que según los hechos probados utilizó Antonio para impactar de refilón en la cabeza de la víctima. Por tanto, el uso de la cadena no se consideró como un elemento que justificara el «animus necandi», en cuanto al medio empleado.

Con respecto al apartado anterior recoge el párrafo segundo de ese fundamento jurídico:

«En el presente caso, se acredita que el instrumento de la agresión fue un arma blanca, un cuchillo, lo que implica la utilización de un medio con gran capacidad lesiva y cortante; la agresión se dirige al tórax, abdomen y cabeza, donde existen evidentemente órganos vitales, prácticamente a flor de piel, alojándose vasos sanguíneos de trascendencia letal; la profundidad de los cortes, es puesta de manifiesto por el dictamen pericial. Además, el médico forense ha señalado que el hemotórax bilateral hubiera ocasionado la muerte de no haberse producido una rápida intervención médica y no porque la víctima estuviera tomando una medicación anticoagulante, sino por la propia naturaleza de la lesión. Estos elementos nos permite inferir la existencia del animus necandi, del ánimo de matar, que implica la calificación jurídica como homicidio, en grado de tentativa, al no haberse producido la muerte, aun cuando se realizaron todos los actos que objetivamente debían producirla y sin embargo, no se produjo por causas independientes a la voluntad del autor (art. 16 Código Penal)».

\footnotetext{
${ }^{20}$ Sobre la distinción entre la intención de lesionar (animus laedendi) y la de matar (animus necandi) la sent. de 10 de julio de 2008 hace un exhaustivo estudio jurisprudencial del tema, poniendo de manifiesto que la única diferencia radica en el ánimo del autor según tenga intención de matar o lesionar. Los criterios para diferenciar ambas situaciones son: «a)Dirección, número y violencia de los golpes. b) Arma utilizada y su capacidad mortífera. c) Condiciones de espacio y tiempo. d) Circunstancias concurrentes. e) Manifestaciones del culpable y actuación del mismo antes y después de los hechos. f) Relaciones autor-víctima. g) Causa del delito».
} 
Todo lo que se recoge en el párrafo anterior, se refiere al otro condenado, Alejandro, sin la más mínima indicción a Antonio.

En todo caso dar un golpe de refilón con una cadena de la que ni siquiera consta su consistencia, ni que fuera en elemento peligroso, no puede llevar a deducir que existiera «animus necandi». La cadena no se llegó a encontrar para incorporarla al procedimiento como prueba.

\section{c) Autoría - Coautoría}

La sentencia se ocupa de la autoría en el fundamento jurídico tercero. Considera que Antonio intervino como coautor ${ }^{21}$; en el fallo se le condena como autor. En todo caso en el párrafo primero del art. 28.1 del Código penal se contempla la autoría directa y la coautoría $^{22}$. Según se desprende de los fundamentos jurídicos la sentencia considera que Antonio intervino como coautor ${ }^{23}$. Autor directo es el que realiza personalmente el hecho típico ${ }^{24}$.

En el párrafo tercero del tercero de los fundamentos jurídicos de la sentencia que se comenta, se recoge:

${ }^{21}$ La sent. del TS 542/2008 de 10 de julio, recoge en el inciso primero del párrafo sexto del sexto de sus fundamentos de derecho: «La moderna doctrina de este Tribunal Supremo establece que la coautoría del art. $28 \mathrm{CP}$ se presenta cuando varias personas de común acuerdo toman parte en la fase ejecutiva de la realización del tipo, codominando entre todos, apareciendo, pues, la autoría como un supuesto de 'división de trabajo', requiriendo, pues, una decisión conjunta, un condominio del hecho, y una aportación al mismo en fase ejecutiva».

${ }^{22}$ Díez Ripollés, J.L., «Una interpretación provisional del nuevo concepto de autor en el Código penal», en Revista de Derecho penal y Criminología, 2a época, 1998, I, pág. 41 dice: «Todo autor tiene que 'realizar el hecho', exigencia objetivo-formal respecto a la cual los aspectos de acceso y control no son más que criterios materiales para su concreción». El autor directo realiza personalmente el hecho típico. La sent. del TS 563/2008 de 24 de septiembre recoge: «Autor directo, según dispone el CP, es quien realiza la acción típica, quien conjuga como sujeto el verbo nuclear de la acción. Característica principal del autor directo es tener el dominio del hecho porque dirige su acción hacia la realización del tipo penal ... La coautoría aparece caracterizada, como hemos señalado, desde el plano subjetivo, por una decisión conjunta de los autores que permite engarzar las respectivas actuaciones enmarcadas de una división de funciones acordadas. Desde el plano objetivo, las acciones de los coautores deben estar enmarcadas en fase de ejecución del delito».

${ }^{23}$ Cerezo Mir, J., Curso de Derecho penal español. Parte General. Madrid: Tecnos, III, 2, en pág. 222 escribe: «La coautoría se produce cuando en la ejecución del delito interviene más de un autor. El nuevo Código penal la recoge en su artículo 28 cuando define como autores a los que realizan el hecho «conjuntamente»... Estamos ante la coautoría, en cambio, cuando varias personas, entre las que existe un acuerdo de voluntades para la ejecución del hecho, realizan cada una de ellas algún elemento del tipo".

${ }^{24}$ La sent. del TS 563/2008 de 24 de septiembre, recoge en el primero de sus fundamentos de derecho: 
«En relación con la coautoría en el homicidio por parte de Antonio, hemos de tener en cuenta que como señala la STS de 22.10 .06 cabe inferir por elementales reglas de lógica, que el acusado tenía que saber o prever que el copartícipe en la agresión llevaba un arma blanca y la alta probabilidad de que hiciera uso de ella contra la persona agredida, como así, efectivamente, habría sucedido, por lo que, si a pesar de esa eventualidad tan razonable y previsible continúa su acción agresiva con el copartícipe en el ataque, se hace corresponsable del apuñalamiento ejecutado materialmente por éste y del resultado del mismo, de acuerdo con lo que se ha llamado "desviaciones previsibles del copartícipe» y el principio de la comunicabilidad en tanto asume que esa acción se puede producir y, a pesar de ello, no abdica de su actuación agresiva contra la víctima común. De este modo, el copartícipe resulta responsable como coautor del resultado final a título de dolo eventual».

La sentencia que se comenta cita la STS de 22.10.2006, en realidad es de 26.10.2006, hay un error en el día ${ }^{25}$. Se trata de la sent. núm. 1037/2006 (Ponente Diego Antonio Ramos Gancedo), que contempla un supuesto de tentativa de homicidio muy distinto del que aquí se debate, ya que en los hechos probados se argumenta la coautoría, lo que no sucede en la sentencia que aquí se comenta. Por tanto, el texto que cita no es aplicable al tema que nos ocupa.

El párrafo tercero del fundamento de derecho cuarto de la sent. de 22-10-2006 (sic) que cita la que se comenta, recoge:

«Ha quedado probado que el acusado está integrado en la banda juvenil de los 'Ñeta', de la que es público y notorio su especial peligrosidad por la violencia con la que ejecutan sus acciones y en las cuales habitualmente portan y emplean armas blancas de distintas características. Armas que en el caso presente aparecen por doquier en las declaraciones testificales, llegando a intervenir la Guardia Civil, dos cuchillos que habían sido abandonados en el autobús».

d) De lo anterior hay que deducir que lo que recoge el párrafo tercero del fundamento jurídico de la sentencia que se comenta, con respecto a la sentencia de 22-10-06 (sic), no es aplicable al caso que nos ocupa, según se desprende de lo que sigue:

a') La sentencia que se comenta dice: «En relación a la coatoría en el homicidio por parte de Antonio, hemos de tener en cuenta que como señala la STS de 22.10.06 cabe inferir por elementales reglas de lógica que el acusado tenía que saber o prever que el copartícipe en la

${ }^{25}$ En los hechos probados de la sent. de 26 de octubre de 2006 (que se corresponde con la de 22.10.2006 que cita la sentencia). Se trata de un error ya que el 22 de octubre era domingo. 
agresión llevaba un arma blanca y la alta probabilidad de que hiciera uso de ella contra la persona agredida».

De los hechos probados no puede deducirse lo que se recoge en el párrafo anterior. No consta que hubieran estado juntos antes de los hechos, sino que Antonio aparece durante la ejecución de los mismos propinando un solo golpe con una cadena que dio de refilón en la cabeza de la víctima, cesando ahí su intervención en unos hechos que continuaron con la participación de otros. Las «elementales reglas de lógica» a que hace referencia la sentencia de 22-10-06, pueden ser válidas para esta sentencia, pero no para la que aquí se comenta, pues los hechos son muy diferentes en ambos casos, como se reflejó más arriba. La lógica, en el tema que nos ocupa, por el contrario, nos llevaría a justificar que Antonio desconocía si el otro condenado llevaba un arma blanca y en consecuencia la probabilidad de que hiciera uso de la misma.

b') Continúa el párrafo indicado: "por lo que, si a pesar de su eventualidad tan razonable y previsible continúa su acción agresiva con el copartícipe en el ataque, se hace corresponsable del apuñalamiento ejecutado materialmente por éste y del resultado del mismo, y de acuerdo con lo que se ha llamado desviaciones previsibles del coparticipe y el principio de comunicabilidad en tanto asume que esa acción se puede producir».

Con respecto al párrafo anterior hay que indicar, como ya se ha dicho anteriormente, que en los hechos probados no se recoge que mi representado conociera que el otro condenado portara un arma blanca, por lo que no se le pueda aplicar la «comunicabilidad»; ni tampoco que asumiera el resultado.

Se dice que "continúa su acción agresiva con el copartícipe». Ello no fue así, pues hay que indicar que realizó un solo acto: se insiste una vez más en que fue un golpe de refilón con una cadena, y nada más. Por tanto, no hubo ninguna continuidad en su acción. No hubo ningún tipo de coparticipación. El acto de Antonio fue aislado, sin ningún acuerdo previo, ni conexión con el otro condenado.

c') Termina el párrafo diciendo: «y, a pesar de ello, no abdica de su actuación agresiva contra la víctima común. De este modo, el coparticipe resulta responsable como coautor del resultado final a título de dolo eventual».

Una vez más se insiste que Antonio sólo realizó un acto, mientras que en el párrafo de la sentencia se dice «no abdica de su ac- 
LA COAUTORÍA EN EL CÓDIGO PENAL A TRAVÉS DE UN SUPUESTO...

tuación agresiva contra la víctima común», lo que no es correcto. Realiza un solo acto y abdica de continuar, en contra de lo que dice la sentencia.

e) Pactum scaeleris y participación adhesiva

Dentro de la autoría, en el párrafo cuarto de este fundamento jurídico tercero, se ocupa la sentencia que aquí se comenta del pactum scaeleris y la participación adhesiva. Recoge:

«También la STS de 14-02-08 señala que "el pactum scaeleris», el concierto de voluntades para cometer un delito, puede ser muy anterior a la acción criminal, inmediatamente anterior o simultáneo a ésta, e incluso posterior al inicio de dicha acción, en lo que se ha denominado "participación adhesiva», cuando el tercero se suma activa y eficazmente a la realización del delito ya iniciado por otros, con la misma voluntad que anima a éstos y asumiendo y responsabilizándose de las acciones precedentes a su incorporación al delito".

Mientras que el pactum scaeleris supone concierto de voluntades para cometer un delito, en la participación adhesiva, según recoge el párrafo anterior, el tercero se suma activa y eficazmente a la realización del delito ya iniciado.

La actuación de Antonio no puede incardinarse en ninguna de ambas situaciones.

En primer lugar hay que indicar que en los hechos probados no se especifica que el leve golpe con la cadena suponía unirse voluntariamente a la acción del otro condenado, y con la intención de causar un homicidio. Tampoco que existiera un acuerdo previo entre los dos condenados, o que Antonio tuviera el dominio o condominio del hecho. Estas cuestiones se tratarán más adelante.

La sentencia para llegar a la conclusión de que Antonio se convierte en coautor tiene en cuenta el contenido de la sentencia de 1402-08. En los hechos probados de esta se reitera que el tercero se suma activa y eficazmente a la realización del delito, lo que no concurre en el supuesto que aquí se debate, como se expuso anteriormente. De otra parte, esta sentencia de 2008 contempla un supuesto de homicidio en grado de tentativa que no es aplicable al caso que nos ocupa, según se desprende de lo que sigue:

La sent. de 14-02-08 se pronuncia sobre el recurso de casación contra la sentencia dictada por la Sección $7^{\text {a }}$ de la Audiencia Provincial de Barcelona de 9 de mayo de 2007. En los antecedentes de la misma se recoge: 
«Son hechos probados, y así se declara, que el día 25 de julio de 2004, alrededor de las dos y media de la madrugada, Alonso acompañado de un grupo de amigos salía de un restaurante sito en la calle Europa de la localidad de Badalona tras celebrar el cumpleaños de uno de ellos. A lo largo de la cena había ingerido bebidas alcohólicas y salieron del restaurante cantando y haciendo ruido lo que motivó la protesta de vecinos de la zona que dada la hora se encontraban durmiendo o tratando de hacerlo; entre esos vecinos se encontraban los dos acusados Braulio y su yerno Ángel Jesús ...

Salieron al balcón, reprochando la actitud de los viandantes, entablándose entre ambos una discusión en el curso de la cual estos lanzaron algún objeto al domicilio de los dos acusados desde el que se arrojó una maceta; la discusión fue subiendo de tono y en un momento de la misma los dos acusados bajaron del domicilio provisto Ángel Jesús de una puntal de obra de dos metros y de un cuchillo de cocina de 32 metros (sic) de hoja, mientras que por su parte Braulio portaba un cuchillo de $21 \mathrm{~cm}$. de longitud de hoja por 5 de anchura. La discusión continuó abajo y en un momento de la misma Ángel Jesús golpeó a Alonso con el puntal en la cabeza ocasionándole un hematoma, lo que motivó que Alonso se quedara levemente aturdido momento que aprovechó Braulio para clavarle el cuchillo que portaba con la intención de acabar con su vida...». El lesionado no falleció a pesar de las graves heridas sufridas.

En la sent. cit de 14-02-2008 se estimó que concurrían el pactum scaeleris y participación adhesiva. Recoge en el párrafo tercero de su fundamento jurídico quinto:

«En el caso presente, repetimos ninguna duda existe de ese concierto de voluntades entre los dos acusados. Se hace referencia también a la participación activa, relevante y eficaz de Ángel Jesús en la ejecución del hecho, con pleno dominio funcional del mismo ... aportación material al hecho que pueda valorarse como una acción esencial y con relevancia causal del resultado producido».

La sentencia de 14-02-2008, que cita la que se comenta, para justificar la coautoría de Antonio, nada tiene que ver con el tema que nos ocupa. Ello se desprende de que en esta sent. de 2008 se argumenta de forma suficiente los elementos que concurren en el supuesto que contempla para motivar la condena; sin embargo, en la sentencia que se comenta no se da ninguno de los elementos que concurren en la de 2008, en cuanto a la intervención de Antonio. a) no hay ni pactum scaeleris (concierto de voluntades para cometer el delito); b) ni "participación adhesiva», ya que Antonio se limitó a dar un golpe de refilón con una cadena, sin más intervención; c) ni realización conjunta del hecho como exige el art. 28 del Código penal; d) su conducta no supuso ninguna acción esencial, 
eficaz y con relevancia causal para el resultado. Sobre todo ello se pronuncia la sentencia indicada anteriormente de 14-02-2008 ${ }^{26}$.

En este sentido y con respecto al pactum scaeleris cabe citar, por todas, la sent. del TS núm. 468, de 18 de mayo de 2007, que se ocupa extensamente de esta cuestión en el párrafo cuarto del quinto de sus fundamentos de derecho. En el apartado 5 se recoge al respecto:

«Que la coautoría presupone la común y unitaria resolución de todos los partícipes para llevarla a efecto, siendo esencial la unidad de conocimiento y voluntad de aquéllos como elemento subjetivo, junto al objetivo de la puesta en práctica de la acción conjunta, debiendo tener la actuación de cada uno la entidad y relevancia precisas que definan al delito».

Ninguno de esos elementos concurre en la actuación de Antonio.

\section{a') Postura de la doctrina}

En cuanto al pactum scaeleris y la coautoría adhesiva o sucesiva, la doctrina no suele ocuparse directamente, sino que suele inclinarse por la fórmula de que el acuerdo puede ser anterior a los hechos, o durante la comisión de los mismos ${ }^{27}$.

Algún autor sí trata directamente esta cuestión manifestando en relación al pactum scaeleris que es necesario un acuerdo previo y aportación real a la ejecución del delito. A este respecto escribe Rodríguez Ramos ${ }^{28}$ :

«La intervención de varias personas en la ejecución de un delito doloso supone, en primer lugar, un acuerdo previo o resolución común de dar cuerpo a la infracción delictiva, con unidad de conocimiento y de voluntad -pactum scaeleris-, que constituye el elemento subjetivo

${ }^{26}$ Recoge la sent. de 14 de febrero de 2008: «La existencia de un plan común de agredir, el contenido del pacto, que se amplía y extiende hasta abarcar la previsible muerte del agredido a la vista de los medios mortíferos empleados por uno de los ejecutores; la persistencia en seguir adelante en el ataque convenido a pesar de esa incuestionable previsibilidad del resultado, la participación activa, relevante y eficaz de Ángel Jesús en la ejecución del hecho, con pleno dominio funcional del mismo. Todo este elenco de circunstancias integran plenamente el concepto de coautoría acogido en el art. 28 C.P. como 'realización conjunta del hecho', que requiere, de una parte, la existencia de una decisión conjunta de ejecutar la acción delictiva como elemento subjetivo de la coautoría. Y, por otra, el elemento objetivo constituido por una aportación material al hecho que pueda valorarse como una acción esencial y con relevancia causal del resultado producido».

${ }^{27}$ CEREzo Mir, en ob. cit., pág. 222 dice que: «El acuerdo de voluntades puede ser anterior o simultáneo»

${ }^{28}$ Rodríguez Ramos, L., Compendio de Derecho penal. Parte general. Madrid: Dykinson, 2010, pág. 198. 
del conjunto que forman el autor o autores directos y los partícipes, y en segundo término el ejercicio de actos por parte de cada uno de los partícipes, incorporando cada cual su aportación real a la ejecución del plan, que tendrán una significación causal en el logro del propósito delictivo o puramente condicional o coadyuvante, que es el elemento objetivo».

Antonio, según los hechos probados, no hizo más que impactar con un simple roce la cabeza de la víctima, utilizando una cadena. En la sentencia en los hechos probados no constan elementos de los que pueda deducirse que hubo concierto de voluntades con el otro condenado para la ejecución del delito, ni aportación real a la ejecución.

- Con respecto a la coautoría adhesiva, escribe:

«El pactum scaeleris no tiene por qué ser formal, previo y expreso, puede ser también tácito y surgir durante la ejecución del hecho (coautoría adhesiva o sucesiva), pues lo definitivo es que acaezca una coincidencia de voluntades de los partícipes que se ha denominado dolo compartido. Ahora bien, el pactum scaeleris no es suficiente por sí sólo para generar coautoría directa o participación, pues como se acaba de ver tiene que existir además un elemento objetivo consistente en una división de aportes o tareas en la ejecución del delito, quehaceres que terminarán asignando a cada cual el título de intervención en el delito que le corresponda» ${ }^{29}$.

Acudiendo a la coautoría adhesiva, tampoco de los hechos probados puede desprenderse que hubiera «una división de aportes o tareas en la ejecución del delito, quehaceres que determinan asignando a cada cual el título de intervención en el delito que le corresponda». Se insiste en que la intervención de Antonio se limitó a un simple refilón utilizando una cadena, sin ninguna intervención posterior.

La acción de Antonio no supuso ningún riesgo para la víctima. Se limitó a un acto sin más actividad. Si hubiera tenido intención de causar la muerte de la víctima, o colaborar eficazmente a ello, hubiera continuado dándole golpes con la cadena.

b') Jurisprudencia

En relación con la participación adhesiva recoge la sent. núm. 563/2008, de 24 de septiembre:

El TS «ha admitido como supuesto de coautoría, lo que se ha denominado participación adhesiva o sucesiva y también coautoría aditiva, que requiere la concurrencia de los siguientes elementos: 1) Que alguien hubiera dado comienzo a la ejecución del delito. 2) Que posteriormente

${ }^{29}$ Rodríguez Ramos, ob. cit, pág. 198. 
otro u otros ensamblen su actividad a la del primero para lograr la consumación del delito cuya ejecución había sido iniciado por aquél. 3) Que quienes intervengan con posterioridad ratifiquen lo ya realizado por quien comenzó la ejecución del delito aprovechándose de la situación previamente creada por él, no bastando el simple conocimiento...».

En la intervención de Antonio sólo podría concurrir el primer apartado: «que alguien hubiera dado comienzo a la ejecución del delito», pero no concurre ninguno de los otros dos.

c') Acuerdo de voluntades (pactum scaeleris) y dominio del hecho

Tanto la doctrina como la jurisprudencia han considerado que el acuerdo de voluntades en los coautores no es suficiente, por lo que se inclinan por el dominio del hecho ${ }^{30}$. En todo caso tanto unos como otros consideran supuestos de dominio del hecho en situaciones en las que el sujeto no participa directamente en la ejecución del delito, sino que lo controla desde fuera. En estos supuestos pueden darse situaciones en las que no será fácil distinguir si quien domina el hecho actúa como cooperador necesario y no como coautor.

La sent. de 18 de mayo de 2007, citada más arriba, que se ocupa extensamente del pactum scaeleris en el punto 7 del párrafo cuarto de su fundamento de derecho quinto recoge:

«La jurisprudencia actual rompe con la idea de que la existencia de un acuerdo previo convierte a los diversos partícipes en coautores, pues conllevaría a un criterio extensivo de autor y calificaría como tal a toda forma de participación concertada, sin tener en cuenta el aporte objetivamente realizado al delito. Por este motivo, la jurisprudencia se ha acercado cada vez más a un concepto de autoría fundado en la noción del dominio del hecho, para el que resulta decisivo, en relación a la determinación de si se ha 'tomado parte directa' en la realización de la acción típica, la posición ocupada por el partícipe en la ejecución del hecho» ${ }^{31}$.

${ }^{30}$ Recoge la sent. 452/2008 cit en el inciso segundo de su fundamento de derecho sexto: «El dominio del hecho, sin embargo, existe aunque cada persona que interviene no realice por sí solo y enteramente el tipo, pues es posible derivar un dominio del echo, en razón a cada aportación al mismo, basada en la división de funciones o del trabajo entre los intervinientes».

${ }^{31}$ Recoge el párrafo sexto del sexto de los fundamentos jurídicos de 10-07-2008: «La moderna doctrina de este Tribunal Supremo establece que la coautoría del art. 28 CP se presenta cuando varias personas de común acuerdo toman parte en la fase ejecutiva de la realización del tipo, codominando entre todos, apareciendo, pues, la autoría como un supuesto de 'división de trabajo', requiriendo, pues, una decisión conjunta, en codominio del hecho, y una aportación al mismo en fase ejecutiva. El dominio del hecho, sin embargo, existe aunque cada persona que interviene no realice por sí solo y enteramente el tipo, pues es posible derivar un dominio del hecho, en razón a cada aportación al mismo, basada en la división de funciones o del trabajo entre los intervinientes». 
En esta línea se pronuncia la jurisprudencia desde hace bastantes años (vid por ejemplo la sent. 08-02-1991).

También la doctrina viene manteniendo la evolución de la jurisprudencia en el sentido de ceder el acuerdo previo a favor del dominio del hecho ${ }^{32}$.

Como ya se ha expuesto anteriormente, no cabe aplicar a Antonio, ni el acuerdo de voluntades (pactum scaeleris), ni que en ningún momento tuviera el dominio o condominio del hecho ${ }^{33}$. Su intervención se limitó simplemente a un acto aislado, sin continuidad; dar de refilón con una cadena a la víctima.

\section{CONSIDERACIÓN FINAL}

El origen de los acontecimientos fue una previa discusión entre dos grupos de jóvenes que terminaría en riña confusa y tumultuaria prevista en el art. 154 del Código penal, donde se castiga a «quienes riñeren entre sí, acometiéndose tumulturiamente, y utilizando medios o instrumentos que pongan en peligro la vida o integridad de las personas, serán castigados por su participación en la riña con la pena de prisión de tres meses a un año o multa de seis a 24 meses» ${ }^{34}$.

Estaríamos ante un delito de peligro que se castiga con la pena indicada por la mera participación en la riña. Sin embargo, si se produjeran resultados lesivos: lesiones o muerte, y se conozcan sus autores, estos serán los que respondan de tales delitos y los demás por la riña ${ }^{35}$. Por tanto Cabrera López sólo podría responder, a lo sumo, por

${ }^{32}$ Sobre el dominio del hecho, vid por todos Díaz y García Conlledo, M., La autoría en Derecho penal. PPU, Barcelona, 1991, págs. 545 y ss.

${ }^{33}$ Muñoz Conde y García Arán, en ob. cit., pág. 437 dicen: «Dominio del hecho, según este criterio, es autor quien domina finalmente la realización del delito, es decir, quien decide en líneas generales el si y el cómo de su realización».

${ }^{34}$ Los hechos en un principio fueron archivados por no conocerse los autores. Más tarde, cuando fueron identificados los dos condenados, más otros que habían participado en las agresiones, el Juez Instructor dictó el siguiente auto: «1 $1^{\circ}$. Declarar procesados a Alejandro por los delitos de homicidio intentado, lesiones y participación en riña y a Antonio por los delitos de homicidio intentado y participación en riña, a quienes se oirán en declaración indagatoria».

${ }_{35}$ Carbonell Mateu, J.C., y González Cussac, J.L., en Comentarios al Código penal de 1995 (Coor. Vives Antón) Valencia: Tirant lo blanch, 1996, I, págs. 803 escriben: «Si en el transcurso de la riña, se causare alguna lesión o muerte al autor, si fuere conocido, habrán de aplicársele los correspondientes tipos de lesiones u homicidio». Esta es la posición dominante en la doctrina. 
una falta de lesiones del art. 617.2, según lo que se establece en los hechos probados de la sentencia.

En relación a lo que se recoge en el párrafo anterior establece la sent. del TS núm. 486/2008, de 11 de julio, en el segundo de sus fundamentos de derecho:

«Bien entendido que cuando se produce el resultado lesivo, tienen preferencia en su aplicación los arts. 147 y concordantes que consumen la ilicitud propia del delito de peligro, aunque obviamente esta punición por la causación del resultado tiene como condición que se conozca el causante de la lesión».

Otra cuestión que podía plantearse es si en los supuestos de riña confusa y tumultuaria, cuando se conoce el autor material de los hechos, como puede ser muerte o lesiones, estamos ante un concurso real de delitos ${ }^{36}$, entre los resultados producidos y el delito de peligro de riña tumultuaria, o las lesiones absorben el delito de riña ${ }^{37}$. En todo caso hay que tener en cuenta que el delito del art. 154 tiene una pena de prisión de tres meses a un año o multa de seis a 24 meses, y la falta del art. 617.2 -malos tratos de obra- localización permanente de dos a seis días o multa de diez a treinta días.

${ }^{36}$ Carbonell Mateu, y González Cussac, en ob. cit., pág. 803 escriben: «Si bien la lesión absorbe el peligro respecto del sujeto pasivo de las lesiones o del homicidio, no lo hace respecto de los demás, por lo que resultará necesaria, en su caso, aplicar las reglas del concurso real de delitos». TAMARIT Sumalla, J.M., en Quintero Olivares, G., (director), Comentarios a la parte especial del Derecho penal Navarra: Thomson-Aranzadi, 2005, en pág. 136, dice que: «La destrucción de la vida o el menoscabo de la integridad absorbe el peligro existente sobre el concreto titular del bien lesionado, pero no el que amenace a otras personas, por lo que, en la medida que no se haya realizado la totalidad del peligro previamente manifestado, los hechos deberán calificarse como concurso real de delitos».

${ }^{37}$ García Arán, M., en Córdoba Roda y García Arán, Comentarios al Código Penal. Parte especial (Directores), Madrid: Marcial Pons, 2004, I, en pág. 127 escribe: «Si se produce muerte o lesiones, dichos tipos de resultado absorberán a la participación en riña, por el principio de que el daño absorbe al peligro». 
20-Seccion abierta Serrano 13/04/2011 13:18 Página 640 